\title{
Development of a transport model for East Kowloon, Hong Kong
}

\author{
D. Thompson, BA, MSc, MIHT, A. Eaglestone, BSc, MSc, MIHT, MCIT, \\ C. O. Tong, BSc, MSc, PhD, MICE, MHKIE and S. C. Wong, BSc, MPhil, PhD, \\ MIHT, MITE, MCIT, MASCE
}

- After the relocation of the airport, much land-use change and redevelopment is expected in the East Kowloon District in the city of Hong Kong. Consequently, a comprehensive review of the land-use and transportation plans for the district was required. In the study, a sub-regional transport model for the district was developed. This model was used to forecast the vehicular, public transport and pedestrian demands arising from land-use and transportation system changes in and around the district. This paper describes the modelling approach and validation results.

Keywords: mathematical modelling; transport planning

\section{Introduction}

Hong Kong has a total area of approximately 1100 square kilometres, of which only around $16 \%$ is built-up because of the many steep hills and remote islands, as shown in Fig. 1. The present population has exceeded 6 million and residential densities are among the highest in the world. ${ }^{1}$

2. The economic success of Hong Kong is well-documented. Early development was stimulated by trade that centred on the natural harbour and the port facilities that grew up around it. The next phase of development was driven by the growth of manufacturing industries. More recently, China has started to attract manufacturing businesses away from Hong Kong because of wage differentials. However, Hong Kong has been quick to adapt and there is a recognition that the future lies in trade, finance and communications.

3. The topography of Hong Kong limits the development of the road system, so public transport is crucial to maintaining the mobility of people and goods. Approximately $80 \%$ of the 10 million person trips made by motorized modes every working day are by public transport. The public transport system is extremely complex with a large number of different modes available, including trams, ferries, light rapid transit (LRT), a mass transit railway (MTR), the Kowloon-Canton railway (KCR), an extensive network of bus services, including services run by four Government-franchised private companies and mini-bus services run by
Government-licensed operators, and about 18000 taxis.

\section{Background}

4. Between 1992 and 2011, the population of Hong Kong is expected to increase from $5 \cdot 5$ million to 8.1 million. The Government has therefore put housing provision near the top of its list of priorities. Much of the additional population will be accommodated in existing new towns in the New Territories, such as Tuen Mun and Yuen Long. The creation of more new towns, such as Tseung Kwan $\mathrm{O}$ and $\mathrm{Ma} \mathrm{On}$

Shan, will also help to satisfy housing demand. However, the existing built-up areas of Kowloon will also have to absorb some of the growth.

5. The relocation of Hong Kong's international airport from Kai Tak in Kowloon to Chek Lap Kok on the island of Lantau will create development opportunities in the traditionally industrial areas of Central and East Kowloon. The reclamation of Kowloon Bay has the potential to provide housing for 300000 people. Also, the removal of height restrictions on new buildings in East Kowloon introduces opportunities for further residential and commercial development. The study area is shown in Fig. 2.

\section{Objectives}

6. The comprehensive traffic review for East Kowloon (CTREK) was a major transport planning study commissioned by the Transport Department (TD) of the Hong Kong Government in 1996. The scope of the study was to prepare Tong and Wong Tai Sin in East Kowloon (current population just below 1 million) for the next 15 years. These improvements will have to be able to cater for the growth in travel demand arising from the development pressures outlined earlier. The study objectives can be specified as

(a) developing a sub-regional transport model (SRTM) for East Kowloon (the study area)

(b) quantifying the vehicular, public transport and pedestrian demands arising from landuse changes in and around East Kowloon

(c) assessing the transport infrastructure requirements to cope with increased transport proposals for the districts of Kwun
Proc. Instn Civ. Engrs Transp., 2000, 141, May, $87-97$

Paper 11891

Written discussion closes 2 November 2000

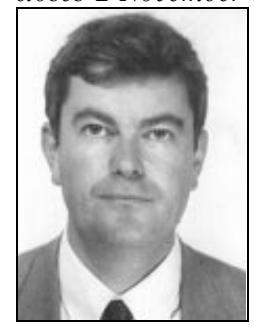

D. Thompson, Associate, Ove Arup \& Partners, United Kingdom

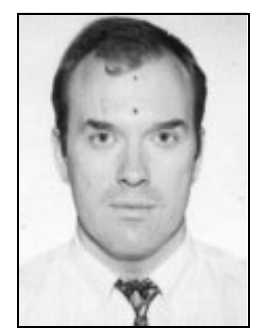

A. Eaglestone, Associate, Ove Arup \& Partners, Hong Kong

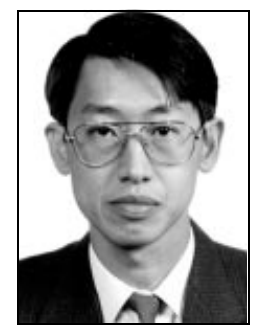

C. O. Tong, Associate Professor, Department of Civil Engineering, The University of Hong Kong

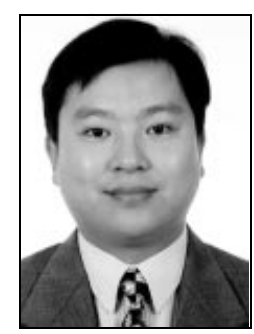

S. C. Wong, Associate Professor, Department of Civil Engineering, The University of Hong Kong 
THOMPSON ET AL.

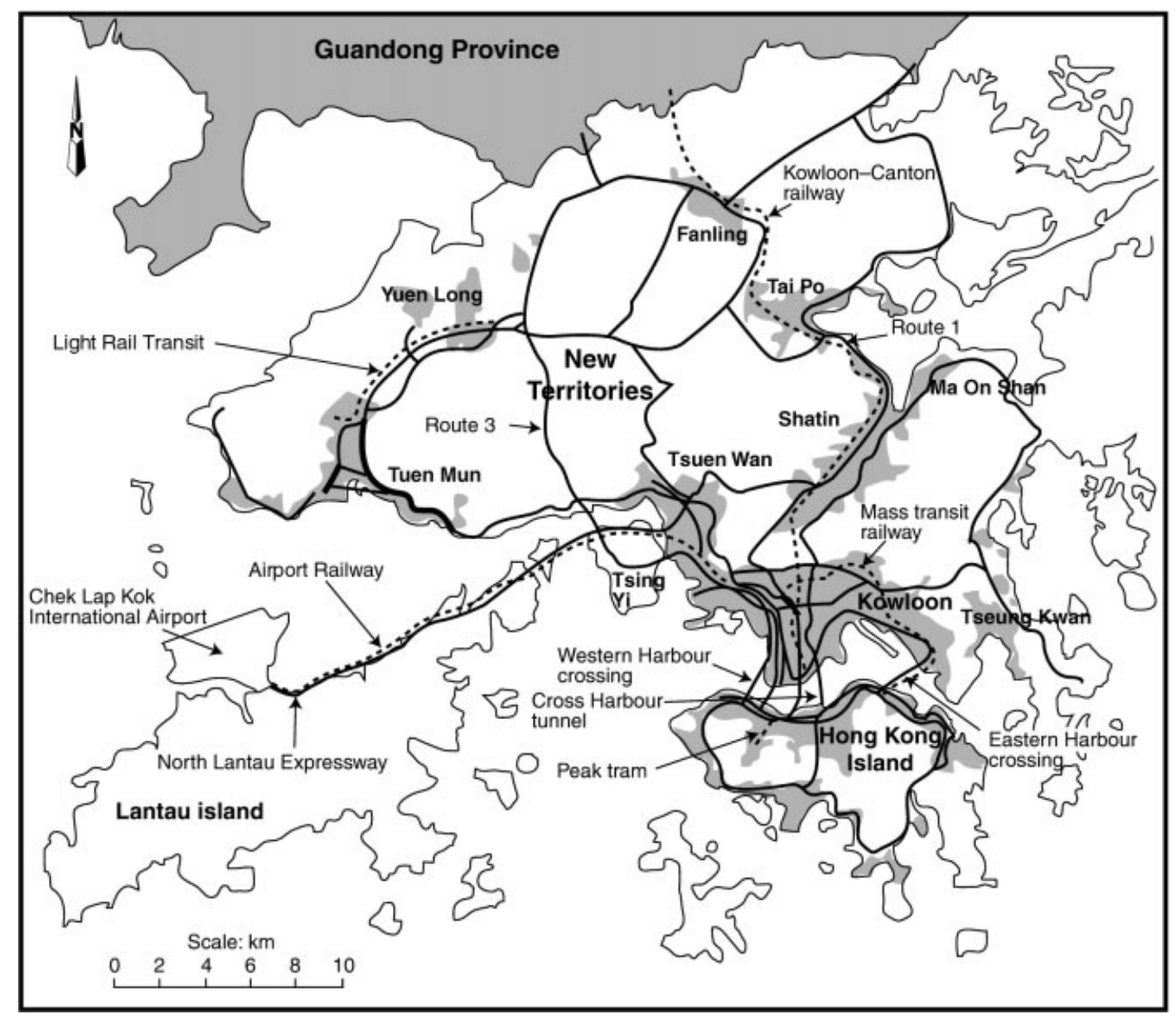

Fig. 1. The city of Hong Kong

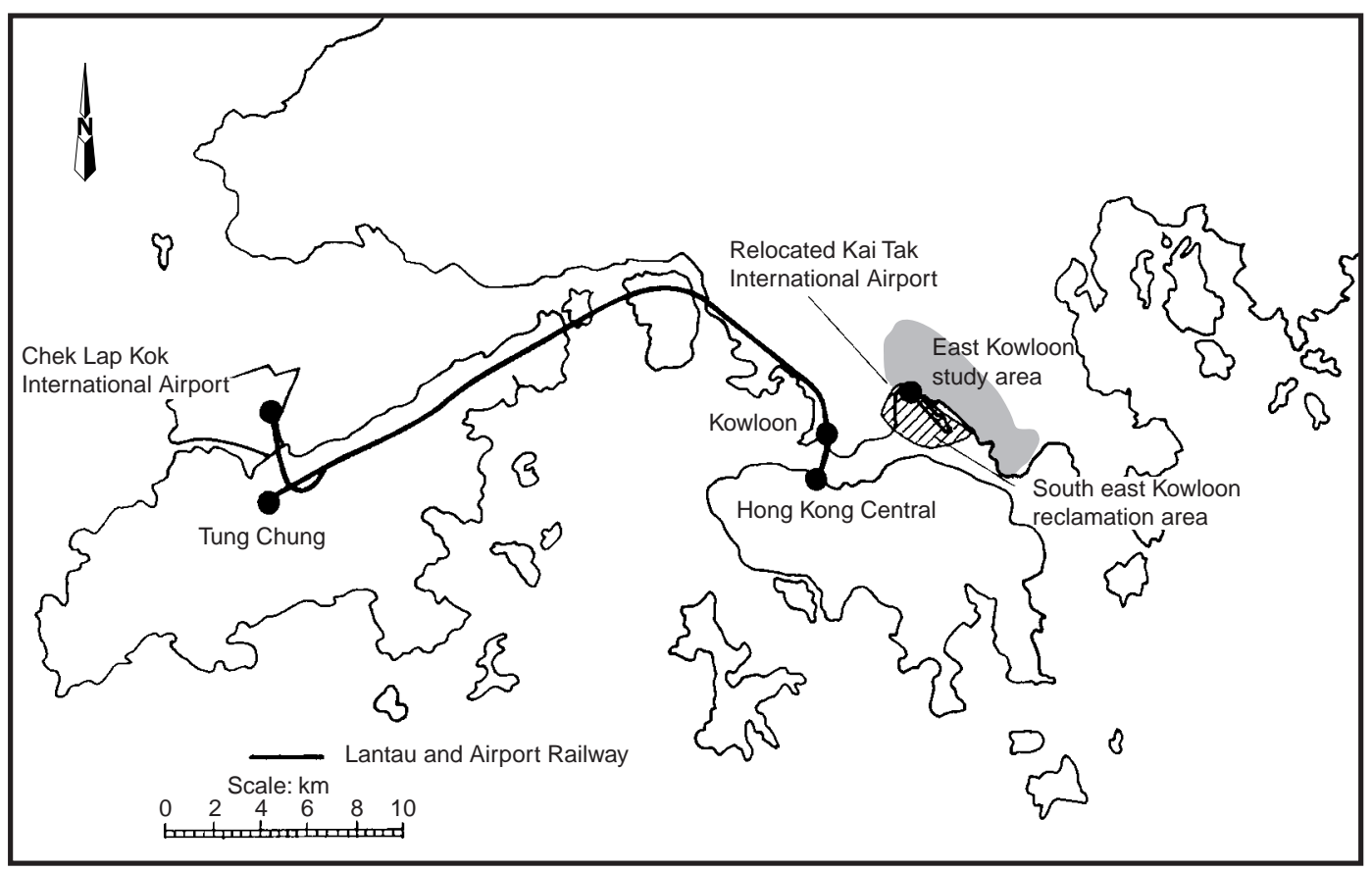

Fig. 2. The study area 
demand for design years of 2001, 2006 and 2011.

\section{Modelling approach}

7. To forecast the transport implications of the significant changes previously outlined, an SRTM was required. The TD specified that this should be a conventional four-stage model with full multi-modal capabilities.

8. Because of the substantial infrastructure developments already planned in and around the study area, it was decided that it would not be adequate merely to concentrate on East Kowloon. Therefore, a territory-wide model was developed, with added resolution in East Kowloon, so that detailed forecasts of local travel patterns could be provided.

\section{Model structure and software issues}

9. The TD has a long-standing comprehensive transport study (CTS) model which was originally developed in the mid-1970s. ${ }^{2}$ It has been progressively improved and updated over the last 20 years. $^{3}$ The latest version was developed during the CTS-2 model enhancement study (CTS2-MES). ${ }^{4}$ The third comprehensive transport study (CTS-3) was commissioned in 1997 and a new transport model is expected to be completed by the end of 1999 .

10. For the SRTM, the general structure of CTS2-MES was retained. The modelling structure is shown in Fig. 3. The main sub-models were as follows

(a) household income distribution

(b) car availability

(c) trip generation

(d) trip attraction

(e) travel costs

(f) modal split

(g) trip distribution

(h) peak period travel

(i) vehicle occupancy

(j) assignment.

11. The network model had 391 zones, 19 modes including franchised buses, public light buses, MTR, Kowloon-Canton heavy rail, trams, LRT and ferries, over 1200 nodes, over 5000 links and almost 1000 transit lines. It was built using the EMME/2 network package.

\section{Data Sources}

12. The most important data source was the 1992 travel characteristics survey (TCS), a major household interview survey in which data were collected from approximately $2 \%$ of households in Hong Kong. ${ }^{5}$ Socio-economic and planning data inputs were provided by the Planning Department (PD) through their Territorial Development Department and also from teams working on studies for Central and East Kowloon and South-East Kowloon. For validation purposes, traffic count data and public

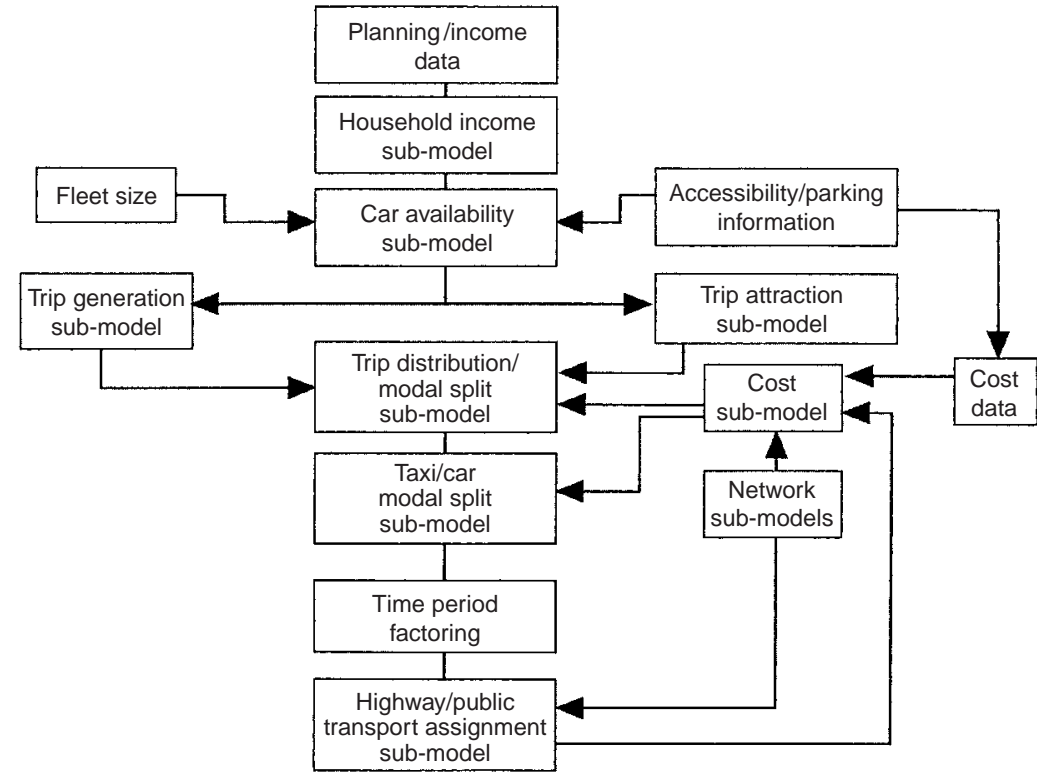

transport occupancy information was obtained from the annual traffic census (ATC) ${ }^{6}$ and surveys commissioned specifically for CTREK.

Fig. 3. SRTM model structure

\section{Household income distribution model}

13. The income distribution model was required to produce a household income distribution for each individual zone which also returned the 'correct' territory-wide income distribution. Hong Kong was divided into five geographical sectors (one being East Kowloon) and four bands for average zonal income were defined

(a) \$0-12000 per month

(b) \$12-18000 per month

(c) \$18-24000 per month

(d) $>\$ 24000$ per month.

Hence, 20 separate curves were defined. A typical set of curves for East Kowloon district is shown in Fig. 4. Each curve had 13 income bands, as listed in Table 1.

14. From zonal average income data for 1991 provided by the PD, each zone was allocated a curve. An iterative procedure was then used to balance the individual zonal income distributions against the territory-wide curve.

\section{Car availability model}

15. The car availability model had a number of key inputs

(a) fleet size (for the whole of Hong Kong)

(b) zonal income distribution

(c) zonal accessibility index

(d) number of residential car parking spaces per household.

16. The car availability for a particular 
Table 1. The income groups for income distribution model

\begin{tabular}{c|c}
\hline Group & Income range: HK\$ per month \\
\hline 1 & $<2000$ \\
2 & $2001-4000$ \\
3 & $4001-6000$ \\
4 & $6001-8000$ \\
5 & $8001-10000$ \\
6 & $10001-15000$ \\
7 & $15001-20000$ \\
8 & $20001-25000$ \\
9 & $25001-30000$ \\
10 & $30001-35000$ \\
11 & $35001-40000$ \\
12 & $40001-50000$ \\
13 & $>50000$ \\
\hline
\end{tabular}

income group in a given zone was determined by a two-stage procedure. In the first stage, the proportion of car-owning households was calculated using the following equation

$$
p_{\text {car }}=\frac{1}{1+\exp \left(a+b I+c \ln I+A_{\mathrm{j}}+P_{\mathrm{k}}\right)}
$$

where $p_{\text {car }}$ is the proportion of car-owning households, $I$ is the household income, $a$ is a constant, $b$ and $c$ are coefficients associated with household income, $A_{\mathrm{j}}$ is the coefficient for accessibility index $j$, and $P_{\mathrm{k}}$ is the coefficient for residential parking index $k$.

17. It was found that the decision of whether a household would own private car(s) is highly dependent on the income level of the household, accessibility by public transport as alternative modes, and residential parking availability. Equation (1) takes the form of representing the effects of these factors by discrete demarcation of the accessibility and parking availability to account for the highly non-linear relationships; and continuous functional form for income level. Moreover, the proportion calculated from equation (1) naturally falls into the meaningful range of $(0,1)$.

18. The second stage further divided the car-owning households into single-car owning and multi-car owning by the following linear equation

$$
p_{\text {multi }}=d+e I+f \ln I
$$

where $p_{\text {multi }}$ is the proportion of car-owning households that is multi-car owning, $d$ is a constant, and $e$ and $f$ are coefficients associated with household income.

19. For multi-car owners, it was found that once the households have decided to own private cars, the number of cars they would own largely depends on how much they can afford to do so, which is highly related to the income level only. The functional form used in equation (2) can effectively model this relationship and produce a better data fit than the logit

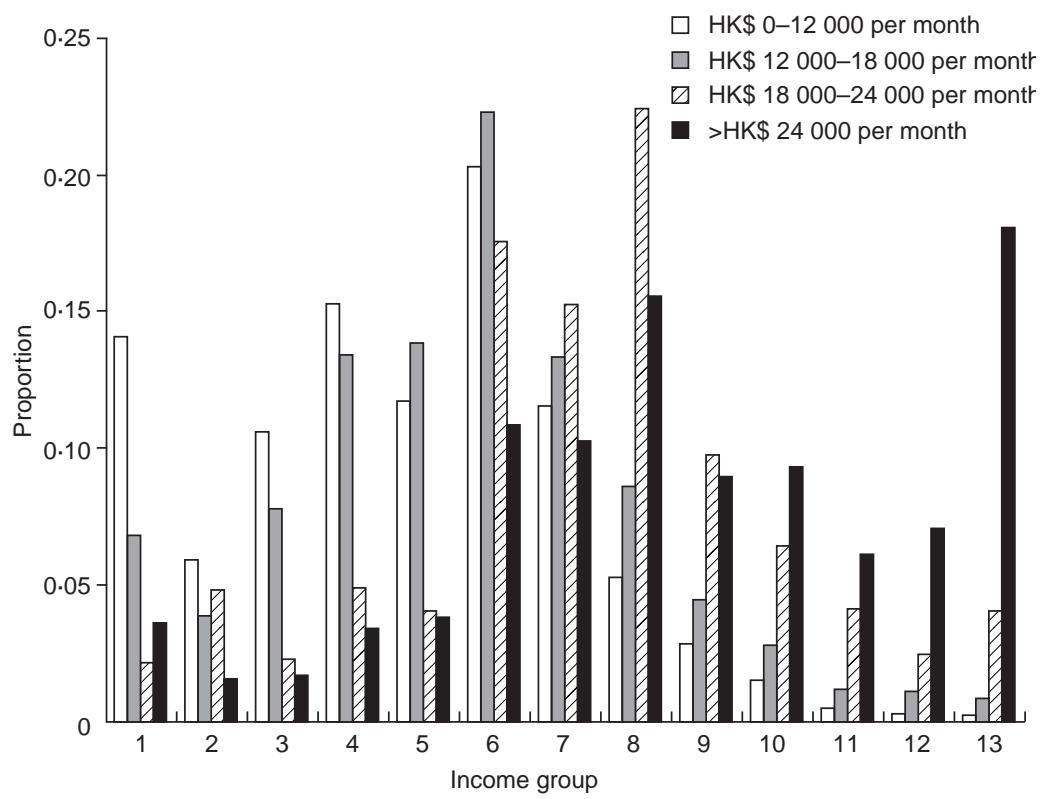

form in equation (1) for the case of multi-car owning.

20. In order to control the model results to agree with the input fleet size, the non-carowning households were multiplied by an adjustment factor $\alpha$ calculated by the following equation

$$
\alpha=1-\frac{\left(F-N_{2}-m N_{3}\right)\left(N_{2}+N_{3}\right)}{N_{1}\left(N_{2}+m N_{3}\right)}
$$

21. The-car owning households including single-car-owning and multi-car-owning households were multiplied by an adjustment factor $\beta$ determined by

$$
\beta=1+\frac{(1-\alpha) N_{1}}{N_{2}+N_{3}}
$$

where $F$ is the target fleet size, $m$ is the number of cars owned by a multi-car household and is taken as $2 \cdot 2$ as determined from TCS, and $N_{1}$, $N_{2}$ and $N_{3}$ are the territory total number of households that are non-car-owning, single-carowning and multi-car-owning respectively.

22 . In 1992, approximately $13 \%$ of households in Hong Kong were car-owning. In East Kowloon, levels of car ownership were even lower with only $8 \%$ of households owning a vehicle. The SRTM model gave a very good representation of both the strategic and local levels of car ownership as shown in Table 2 .

\section{Trip generation model}

23. The trip generation model had six trip purposes as follows

(a) home-based work, high income (HBWH)

(b) home-based work, low income (HBWL)

(c) home-based shopping (HBS)

(d) home-based other (HBO)

(e) non-home-based (NHB)

$(f)$ employer's business (EB).
Fig. 4. The income distribution curves for East Kowloon 
24. The model also had two car availability groups

(a) no car available

(b) car available.

25. The trip generation equations were taken from CTS2-MES and had the following general format

$$
R=\frac{Z_{\mathrm{i}}}{1+\exp \left(u+v I+w \ln I+G_{\mathrm{j}}+A_{\mathrm{k}}+C_{\mathrm{i}}\right)}
$$

where $R$ the trip generation rate; $I$ is the household income; $u$ is a constant; $v$ and $w$ are coefficients associated with household income; $Z_{\mathrm{i}}$ is the asymptote of trip generation rate for car availability category $i$ (where $i=1$ for a non-car-owning household, $i=2$ for a single car-owning-household and $i=3$ for a multi-carowning household as defined in the car availability model); $G_{\mathrm{j}}$ is the coefficient for age category $j ; A_{\mathrm{k}}$ is the coefficient for zonal accessibility category $k$; and $C_{\mathrm{i}}$ is the coefficient for car availability category $i$.

26. Similar to the car availability model, equation (5) takes a logit form to represent the highly non-linear relationships between trip generation rate and significant parameters such as age, accessibility by public transport and car availability by discrete demarcation; and that with the income level by a continuous functional form. The asymptote used in equation (5) is to cap the trip generation to the maximum generation capacity in a zone. The values of the coefficients in the equation were compatible with those from CTS-2MES. The trip rates for HBWH, HBWL and EB were based on trips per worker, for HBS on trips per student, and those for HBO and NHB were based on trips per person.

27. In 1992 in Hong Kong there were approximately 10 million person trips per day, of which about $36 \%$ were home-to-work trips. Comparison between modelled and observed (TCS) trip generation by trip purpose and car availability group showed a good level of agreement, both for the whole of Hong Kong and in East Kowloon, as listed in Table 3.

\section{Trip attraction model}

28. The 1992 TCS data provided information on the number of trips attracted at each zone and the zonal planning data provided information on the number of jobs (divided into twelve categories), school places, markets, cinemas, hospital beds and hotel rooms.

Equations relating trip attraction and land-use variables were developed for each trip purpose using stepwise regression analysis. Wherever there were sufficient data, separate coefficients were developed for each of five geographical sectors, one of these being East Kowloon. Total trip attractions for Hong Kong were controlled to total trip generations in the usual way.
Table 2. Comparison of Car Ownership Estimates

\begin{tabular}{l|c|c}
\hline \multirow{2}{*}{ Model output } & \multicolumn{2}{|c}{1992 base year } \\
\cline { 2 - 3 } & Observed & Modelled \\
\hline Hong Kong car ownership: & & \\
0 car households & $1 \cdot 39$ million & $1 \cdot 38$ million \\
1 car households & $0 \cdot 18$ million & $0 \cdot 18$ million \\
$2+$ car households & $0 \cdot 02$ million & $0 \cdot 03$ million \\
\hline East Kowloon car ownership: & & \\
0 car households & 239000 & 240000 \\
1 car households & 18500 & 17400 \\
$2+$ car households & 1100 & 1500 \\
\hline
\end{tabular}

Table 3. Comparison of trip generation estimates

\begin{tabular}{l|c|c}
\hline \multirow{2}{*}{ Model output } & \multicolumn{2}{|c}{1992 base year: millions } \\
\cline { 2 - 3 } & Observed & Modelled \\
\hline Total person trips per day & $10 \cdot 30$ & $10 \cdot 30$ \\
Trips from car-owning households & $2 \cdot 18$ & $2 \cdot 18$ \\
Trips from non-car-owning households & $8 \cdot 12$ & $8 \cdot 12$ \\
\hline Person trips per day by car & $1 \cdot 18$ & $1 \cdot 24$ \\
Person trips per day by taxi & $0 \cdot 86$ & $0 \cdot 88$ \\
Person trips per day by public transport & $8 \cdot 26$ & $8 \cdot 18$ \\
\hline East Kowloon screen line (KK): & & \\
Person trips per day by car & $0 \cdot 17$ & $0 \cdot 17$ \\
Person trips per day by taxi & $0 \cdot 10$ & $0 \cdot 11$ \\
Person trips per day by public transport & $1 \cdot 02$ & $1 \cdot 06$ \\
\hline
\end{tabular}

\section{Cost models}

29. As trip cost is an important determinant of travel behaviour, a detailed cost model was developed. For private vehicle trips, the generalized cost of a trip was composed of trip time, a distance-related vehicle operation cost, tolls and parking costs. Information on parking duration and parking charges was taken from a recently completed parking demand study. ${ }^{7}$ The monetary value of travel time, which depended on trip purpose and income, was determined by a stated preference survey conducted in the 1992 TCS. To determine the cost of taxi trips, the taxi fare structure, which was distancebased, was incorporated. For public transport trips (as most transit modes, such as buses, mini-buses, trams and ferries, charged flat fares) the fare was represented simply as boarding penalties. However, fares for the MTR, and the KCR are broadly distance-based and were therefore incorporated into specific rail links. The various cost components of trips by various modes are summarized in Table 4 .

\section{A combined trip distribution and main modal} split model

30. The trip distribution model used the following standard gravity model formulation

$$
T_{\mathrm{ij}}=a_{\mathrm{i}} b_{\mathrm{j}} U_{\mathrm{i}} V_{\mathrm{j}} \Gamma\left(c_{\mathrm{ij}}\right)
$$


where $U_{\mathrm{i}}$ is the productions in zone $i ; V_{\mathrm{j}}$ is the attractions in zone $j ; c_{\mathrm{ij}}$ is the measure of the separation between zone $i$ and zone $j$, expressed in terms of generalized cost (equivalent minutes); $\Gamma($.$) is the function expressing the$ relative probability of trips occurring for any given cost value (termed the distribution function); and $a_{\mathrm{i}}, b_{\mathrm{j}}$ are balancing factors.

31. The difficulty of estimating the generalized trip cost, $c_{\mathrm{ij}}$, when the trip mode was not yet known was overcome by combining the trip distribution and main modal split models. The main modal split model would estimate the proportion of trips by private or public transport modes for each origin destination zone pair for car-owning and non-car-owning households. For trips from car-available households, the private travel times and costs were based on private car times and costs. For those from noncar-available households, they were based on taxi travel times and costs. The value of $c_{\mathrm{ij}}$ is then assumed to be a weighted average of the generalized costs by private and public modes.

32. Separate distribution functions were developed for each trip purpose and car availability group. Also, a six-sector system was used in the calibration process, and the model was calibrated separately for seven sector-tosector movements. This was necessary because of the unique physical layout of Hong Kong, resulting in different trip distribution characteristics for each trip movement category. For example, cross-harbour trips were treated as a separate category because the shortage of cross-harbour road links is a major constraint on travel.

33. Using the TCS trip data, the distribution functions were calibrated using three-dimensional balancing. ${ }^{8}$

34. Multiplying the main modal split proportions by the synthesized matrices from the gravity model gave a further set of matrices containing trips by purpose, car availability group and main mode (private or public).

35. The car/taxi modal split sub-model was used to divide the private trip matrices output from the trip distribution model into car and taxi trip matrices. Once again, separate relationships were developed for each trip purpose and for individual sector-to-sector movements.

36. The results from the trip generation, modal split and distribution models were checked by looking at total daily trips by mode, and screen line crossings by mode. In general, the model results seemed to be in good agreement with the observed data. This is discussed in more detail later in the paper.

\section{Peak period models}

37. The SRTM had two peak periods

(a) $07: 45-09: 30$

(b) $16: 45-18: 30$.
Table 4. Cost model components

\begin{tabular}{l|l|l}
\hline Mode & Travel time components & Travel cost components \\
\hline Car & $\begin{array}{l}\text { Time in origin zone } \\
\text { Inter-zonal travel time } \\
\text { Parking search time } \\
\text { Time in destination zone }\end{array}$ & $\begin{array}{l}\text { Operating costs } \\
\text { Toll charges } \\
\text { Parking costs }\end{array}$ \\
\hline Taxi & As car travel time & Taxi fares \\
\hline Public transport & $\begin{array}{l}\text { Walk time } \\
\text { Wait time } \\
\text { In-vehicle time }\end{array}$ & PT fares \\
\hline
\end{tabular}

Note: Car and taxi costs are adjusted for vehicle occupancy.

The peak period factors for each mode and trip purpose were calculated from the TCS data.

Hong Kong was divided into 16 sectors, including one each for Kwun Tong and Wong Tai Sin districts, to ensure that representative peaking characteristics were applied in all cases. For example, home-to-work trips from towns in the New Territories into Kowloon or Hong Kong Island tend to start earlier than trips with both ends within the built-up areas close to the main centres of employment.

\section{Vehicle occupancy}

38. Vehicle occupancy models for cars and taxis from the CTS2-MES model were used directly in SRTM. These relate journey distance to occupancy using the following general formula with unique coefficients for each trip purpose

$$
\Omega=g+h x
$$

where $\Omega$ is the average car occupancy, $g$ is the calibrated constant, $h$ is the calibrated coefficient, and $x$ is the distance of travel.

\section{Heavy goods vehicles and special-purpose buses}

39. A goods vehicle model was not developed specifically for the study. The TD provided trip matrices for heavy goods vehicles from the recent freight transport study model. ${ }^{9}$ Special-purpose buses (SPB) are school and works buses that do not follow fixed routes. Matrices for these trips were estimated from CTS2-MES ${ }^{4}$ as input to the study.

\section{Assignment models}

40. The SRTM assignment models represented travel conditions in an average hour within the peak periods previously identified. In the highway model, four user classes were defined
(a) car
(b) taxi
(c) SPB
(d) goods vehicles. 
41. Volume-delay functions were calibrated, based on the speed-flow curves in CTS2-MES. These covered the following general link types

(a) rural roads

(b) rural trunk roads

(c) urban local distributors

(d) urban district distributors

(e) urban primary distributors

$(f)$ urban trunk roads

(g) expressways.

42. As a large percentage of the trips are by public transport, the urban area is served by a dense multi-modal public transport system consisting of buses, mini-buses, trams, the MTR and ferries. The heavy demand makes it viable to provide multi-modal transit services along common corridors. Many trips use more than one mode; for example, a person may use a feeder bus/mini-bus line to travel to the rail station and then continue by rail.

43. For these reasons, it was decided, in SRTM, to combine the public transport submodal split and assignment models. It is believed that this combined model could capture the characteristics of the multi-modal network and trip chaining behaviour more accurately. Consequently, a multi-modal transit network was built and the total public transport demand matrix was assigned to this network. This network consisted of road links, rail links as well as ferry links. Bus and minibus lines were built along road links. Bus travel speeds were adjusted to reflect the impact of highway congestion on their operations.

However, roads with bus lanes were modelled by assuming that bus speeds were independent of general traffic speeds on the links in question.

\section{Implementation of the model}

44. The suite of transport models described was implemented in the EMME/2 computing platform, taking full advantages of the functionality in the software packages, such as multi-modal assignment, stochastic transit modelling and macro operations. ${ }^{10}$

\section{Model validation}

45. The validation process was split into a number of separate exercises as follows.

(a) Checks were made on the validity of the trip generation/attraction and modal split and trip distribution sub-models by assessing the accuracy of total daily modelled trips by mode and trip purpose for the whole territory.

(b) Modelled crossings of key ATC/CTS screen lines (Fig. 5) were compared with 1992 observed data.

(c) A thorough check of the network models was carried out to ensure that they gave a satisfactory representation of the highway and public transport systems in East Kowloon and the surrounding area.

(d) An a.m. and p.m. peak link flow validation exercise was carried out on a cordon around the study area and a series of local screen lines to ensure that highway volumes output by the model accorded with 1996 observations.

(e) Modelled highway travel times across the CTREK study were compared with observed travel times to ensure that the model was simulating realistic speeds.

( $f$ ) The modelled passenger flows on MTR, bus and KCR were compared with observed data to verify that the model was giving a good representation of 1996 travel patterns.

46. To assess the validity of the trip generation/attraction and modal split and trip distribution sub-models, the overall number of daily trips by mode within the Territory as estimated by SRTM was compared with 1992 data from TCS. In general, the comparison between SRTM modelled daily trips and the TCS observed totals by mode and trip purpose was considered to be very satisfactory.

47. Modelled volumes produced from the 1992 SRTM assignment model were compared with observed daily person screen-line crossings quoted in the CTS2-MES report (shown in Figs 6 and 7). Taking the modes under consideration - car, taxi, total private transport-(i.e. car plus taxi) and public transportthere were 48 sets of data to compare. In 39 cases $(81 \%)$, the difference between modelled and observed flows was less than or equal to $\pm 10 \%$. Only four cases were outside the range $\pm 15 \%$ and three of these were on screen lines which are remote from East Kowloon. Consequently, the SRTM modal split and trip distribution sub-models were considered to give an acceptable representation of travel behaviour both within and around the study area.

48. The SRTM a.m. and p.m. peak assignment models were validated by comparing modelled and observed 1996 link flows across a cordon around the study area as well as a series of local screen lines (Fig. 8). In total there were nine screen lines where comparisons could be made between modelled and observed flows. Taking into account directions of flow and the two peaks under consideration, this gave a total of 36 comparisons, representing a very rigorous test of the robustness of the model. In 28 cases out of 36 , the difference between modelled and observed screen line crossing flows was less than $\pm 10 \%$. Only five cases were outside a range of $\pm 15 \%$. These differences tended to occur on the less heavily trafficked screen lines (Fig. 9). 


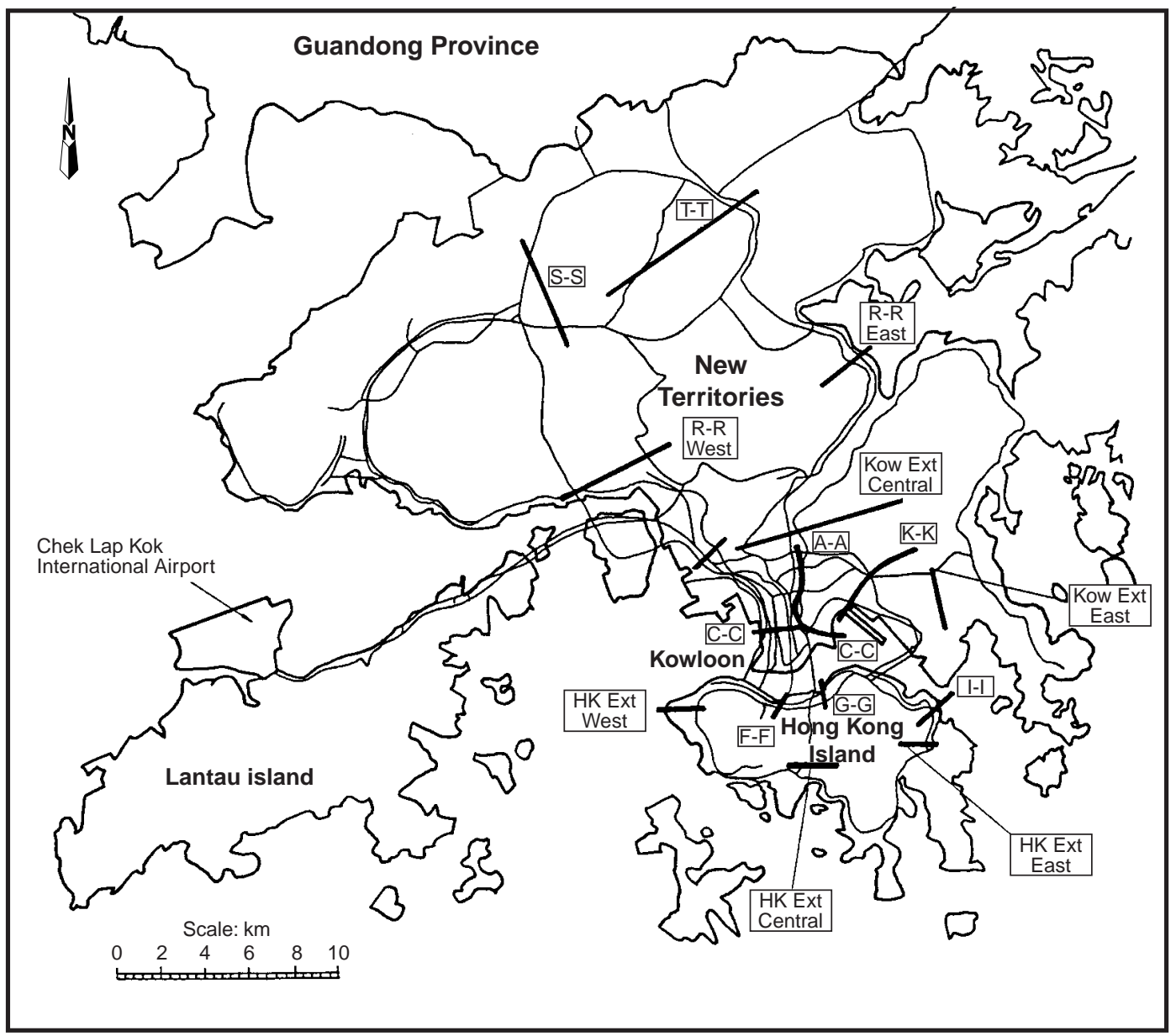

Fig. 5. ATC/CTS screen lines

49. The external cordon and one central screen line were also used to carry out a validation exercise for the assignment of public transport trips. The ATC data provided passenger volumes in addition to vehicular flows. These were extracted for the 1996 model a.m. and p.m. peak periods. In general, the standard of validation expected from a public transport model is not as high as that expected from a highway model. However, the total 1996 modelled cordon and screen line crossings in each peak period were within $\pm 25 \%$ of observed flows in almost all cases.

50. Within the study area there were eight sections of MTR line where the model performance was assessed. In general, the difference between modelled and observed passenger flows was within a range of $\pm 20 \%$. This demonstrated that the model gave a very good representation of local demand for the MTR, and that the assignment process in EMME/2 gave a realistic split of public transport trips between bus and rail modes.

51. The Mass Transit Railway Company also provided 1996 observed passenger flows for each of the stations within the study area and these were compared with the boarding and alighting totals in the model. In general, the model gave a reasonable representation of

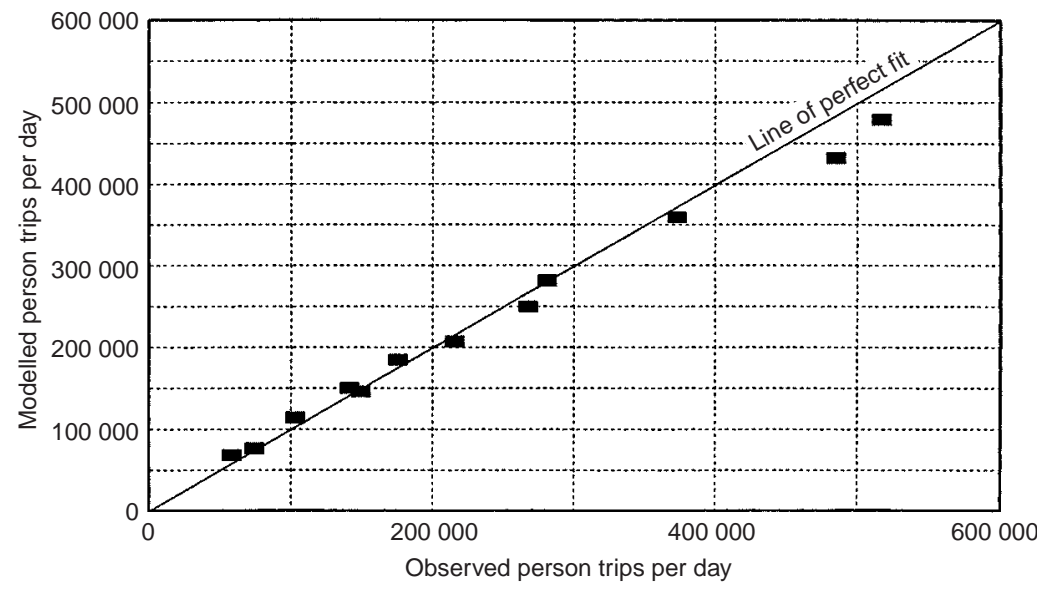

observed flows into and out of each station in the peak periods under consideration.

\section{Transport forecasts for East Kowloon}

52. Demand forecasts were produced for three horizon years: 2001, 2006, and 2011. The population forecasts are shown in Table 5.

These drew on planning data from the territory development strategy and data from the teams working on the Central and East Kowloon study and the South-East Kowloon study. Sensitivity tests were also run with a higher intensity of
Fig. 6. Comparison of screen line counts for private trips (car, taxi) 
Table 5. Population forecasts

\begin{tabular}{l|c|c|c|c}
\hline \multirow{2}{*}{ Scenario area } & \multicolumn{4}{|c}{ Population in millions } \\
\cline { 2 - 5 } & 1996 & 2001 & 2006 & 2011 \\
\hline Scenario A1: & & & & \\
Hong Kong & 6.00 & 6.65 & 7.20 & 8.09 \\
East Kowloon & 0.94 & 0.96 & 0.89 & 11.01 \\
\hline Scenario A2: & & & & \\
Hong Kong & 6.00 & 6.65 & 7.27 & 8.32 \\
East Kowloon & 0.94 & 0.96 & 0.96 & 1.17 \\
\hline
\end{tabular}

residential development in East Kowloon. This was known as scenario A2 and the assumptions used are summarized in Fig. 10. Further tests were also carried out with changes to the assumed future car fleet size for the whole of Hong Kong.

53. Growth in highway demand was assessed by comparing traffic flows across validation screen lines between forecast years. The results show that traffic flows into and out of East Kowloon in the peak periods can be expected to grow by $54-68 \%$ between 1996 and 2011. From the KK screen line, which runs through the heart of the study area, it can be seen that, locally, traffic flows could double if all the expected developments proceed (Fig. 11).

54. It was found that, at a strategic level, some of the traffic growth could be absorbed by planned major road projects, such as

(a) Western Coast Road

(b) Kai Tak Connector

(c) Hung Hom-Kai Tak Link

(d) Central Kowloon Route.

55. However, a large number of additional local road schemes, junction improvements and traffic management proposals also had to be prepared to deal with the consequences of the traffic growth anticipated. The SRTM results were used extensively in sizing these schemes.

56. Public transport demand in East

Kowloon is also expected to grow substantially between 1996 and 2015, as discussed later. Again, there are planned rail projects which will help to cater for this growth, including the MTR Tseung Kwan O Extension, which links the new town with the CTREK study area. The SRTM forecasts demonstrated that this scheme is an essential element of the transport strategy for the next century and that demand levels will rise rapidly in the early years of operation as Tseung Kwan O grows towards a population of around 0.5 million by 2011 .

\section{Conclusions}

57. The SRTM EMME/2 model was created with a view to providing a sub-regional multimodal model for East Kowloon with a strategic forecasting capability. This was achieved using

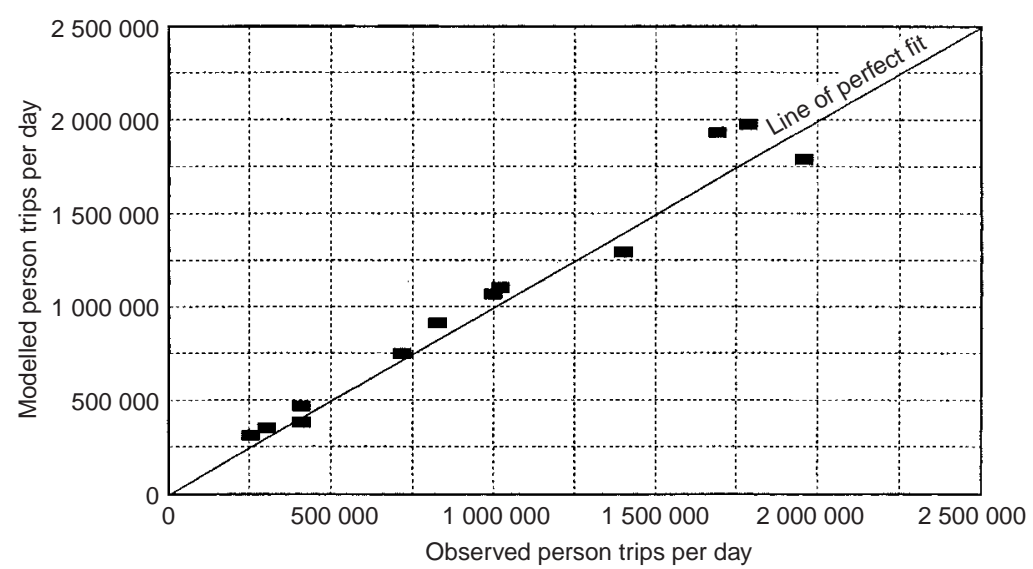

Fig. 7. Comparison of screen line counts for public transport trips

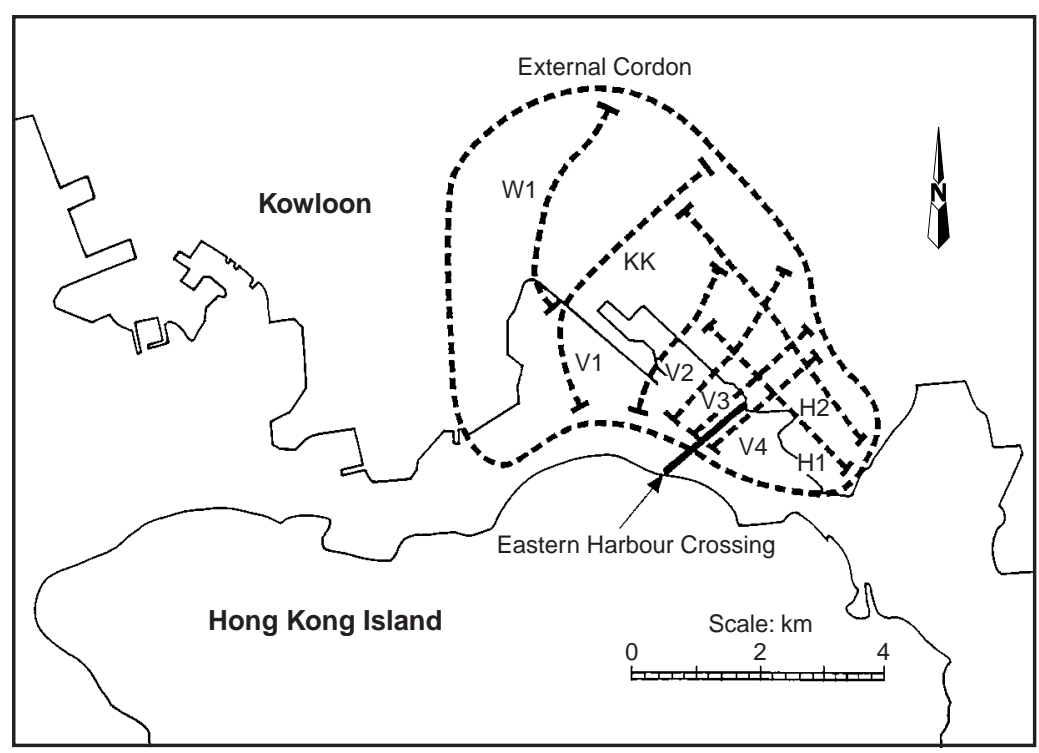

Fig. 8. Local validation screen lines

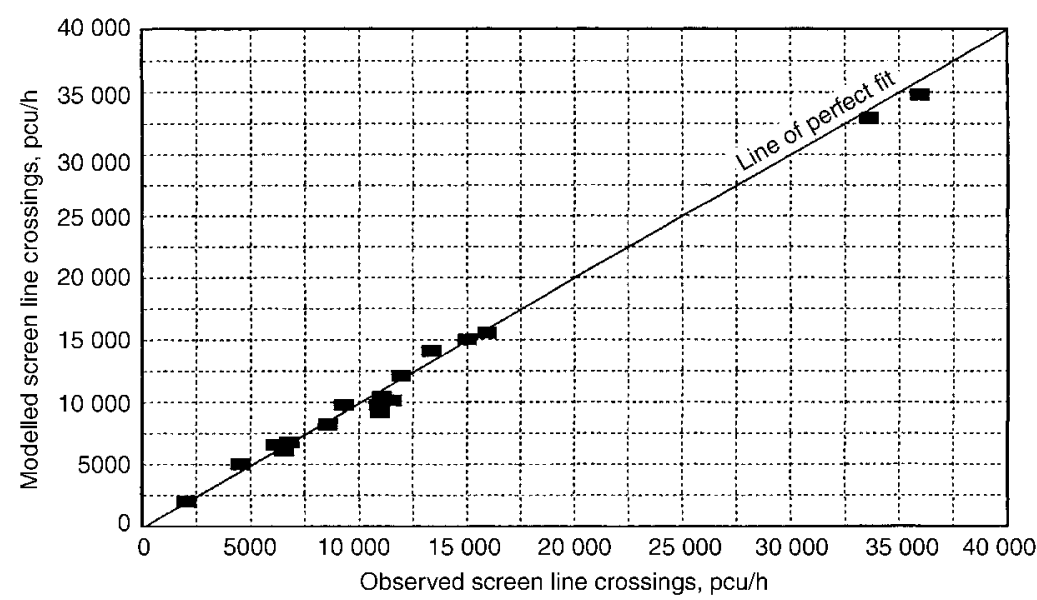

Fig. 9. Local screen line validation (highway model-a.m. peak) 
a mixture of new models calibrated from TCS household interview data and models imported into EMME/2 from CTS2-MES. A reasonable standard of validation was achieved at both strategic and local levels.

58. The SRTM forecasts confirmed that the major investments in new transport infrastructure that are planned in this area are required to cater for the anticipated increases in transport demand. In particular, the MTR Tseung Kwan O Extension and the Western Coast Road are vital components of the strategy to expand Tseung Kwan $\mathrm{O}$ without causing undesirable side-effects in East Kowloon. In addition, the SRTM forecasts demonstrated that a large number of local transport improvements would be required to support the housing plans in East Kowloon and the side-effects of the reclamation and development of Kowloon bay.

59. Using the demand forecasts from the SRTM, the CTREK study produced a transport plan for East Kowloon including proposals for the following

(a) highway schemes

(b) traffic management schemes

(c) junction improvements

(d) improvements to public transport operations

(e) park-and-ride schemes

(f) pedestrian schemes

(g) parking schemes.

60. The SRTM model was set up in such a way that relatively inexperienced EMME/2 users could operate it with limited training. Full model runs take about 16 h. Highway assignments take $30-45 \mathrm{~min}$.

61. Any model can be further improved and the SRTM model is no exception. First, as congestion in the transit network occurs frequently during peak hours, the public transport assignment model could be improved by the development of a capacity-restrained procedure. At present, with most commercially available network packages, it is not possible to carry out a capacity-restrained transit assignment. The EMME/2 suite adopts a stochastic model for transit network assignment. Second, the air quality in the urban areas has deteriorated rapidly in recent years, due mainly to vehicle emissions. An air quality impact model should therefore be included. Third, the presentation of model outputs can be enhanced by incorporating geographic information system (GIS) capability into the model.

\section{Acknowledgements}

62. The Transport Department of the Government of the Hong Kong Special Administrative Region is acknowledged for giving permission to publish a paper based on the work of the study Comprehensive Traffic Review for East Kowloon. ${ }^{11}$ The authors are grateful to

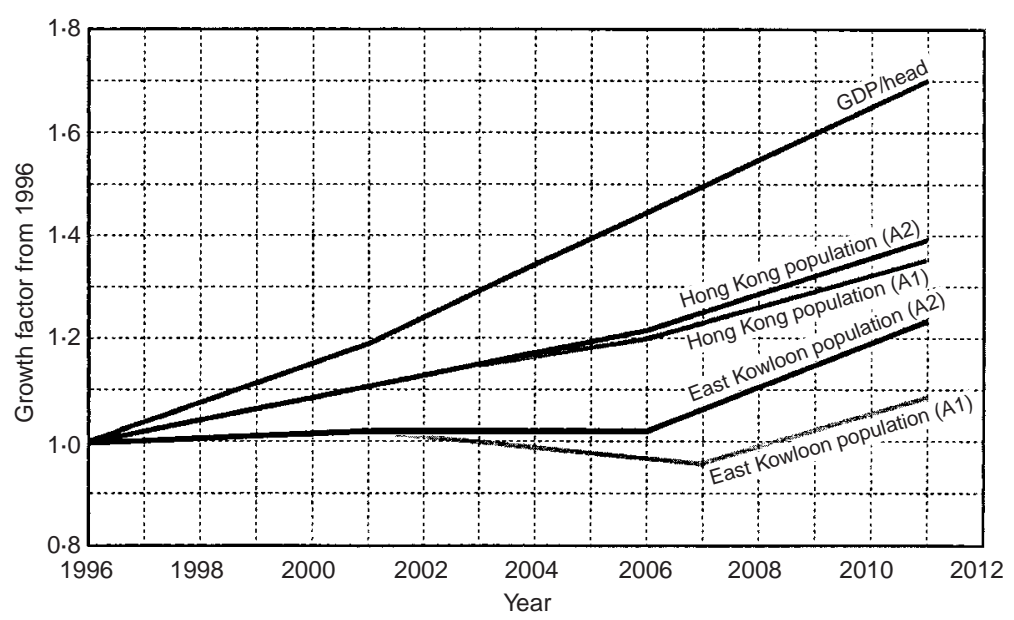

Fig. 10. Socio-economic forecasts

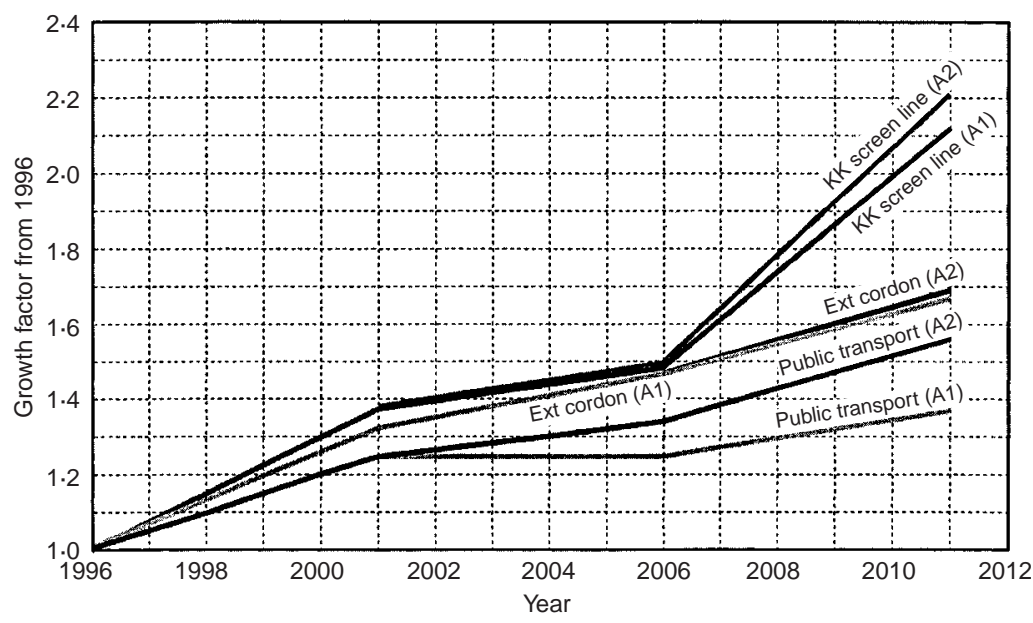

Fig. 11. Travel demand forecasts

Alex Yeung of the Transport Department for his assistance with the study, Eleanor Clark and Stephen Yeung for their hard work with model calibration, validation and forecasting.

\section{References}

1. Information Services Department. Hong Kong 1998. Hong Kong Government, Hong Kong, 1999.

2. Transport Department and Wilbur Smith and Associates. Hong Kong Comprehensive Transport Study_Final Report. Transport Department, Hong Kong Government, Hong Kong, 1976.

3. Transport Department and Wilbur Smith and Associates. Hong Kong Second Comprehensive Transport Study - Final Report. Transport Department, Hong Kong Government, Hong Kong, 1989.

4. Transport Department and Wilbur Smith and Associates. Conversion and Enhancement of Second Comprehensive Transport Study Computer Programs-Final Report. Transport Department, Hong Kong Government, Hong Kong, 1995.

5. MVA Asia. Travel Characteristics Survey-Final Report. Territory Transport Planning Division, 
Transport Department, Hong Kong Government, Hong Kong, 1993.

6. Transport Department. The Annual Traffic Census 1992. TTSD, Hong Kong Government, Hong Kong, 1993.

7. Transport Department and Ove Arup and Partners. Parking Demand Study - Final Report. Traffic and Transport Survey Division, Transport Department, Hong Kong Government, Hong Kong, 1995.

8. Evans S. P. and Kirby H. R. A three-dimensional Furness procedure for calibrating gravity models. Transportation Research, 1974, 8, 105-122.
9. Transport Department and Scott Wilson KIRKPATRICK. Freight Transport Study-Final Report. Territory Transport Planning Division, Transport Department, Hong Kong Government, Hong Kong 1994.

10. INRO Consultants Inc. EMME/2 User's Manual. INRO Consultants Inc., 1996.

11. Transport Department and Ove Arup and Partners. Comprehensive Traffic Review for East Kowloon-Final Report. Traffic and Transport Survey Division, Transport Department. The Government of Hong Kong SAR, Hong Kong, 1998.

Please email, fax or post your discussion contributions to the secretary:

email: wilson_1@ice.org.uk; fax: + 44 (0)20 7799 1325; or post to Lesley Wilson, Journals Department, Institution of Civil Engineers, 1-7 Great George Street, London SW1P 3AA. 